\title{
A Comparison of the Ability of Fungal Internal Transcribed Spacers and D1/D2 Domain Regions to Accurately Identify Candida glabrata Clinical Isolates Using Sequence Analysis
}

\author{
Min-Ji Kang ${ }^{1, \S,}$, Yoon-Sung Choi ${ }^{1,2, \S, * *}$ and Sunghyun Kim ${ }^{1,2, ;, * * *}$ \\ ${ }^{1}$ Department of Clinical Laboratory Science, College of Health Sciences, \\ Catholic University of Pusan, Busan 46252, Korea \\ ${ }^{2}$ Clinical Research Specialist Program for In Vitro Diagnostics, Brain Busan 21 Plus Program, \\ Graduate School, Catholic University of Pusan, Busan 46252, Korea
}

Candida glabrata is the second most prevalent causative agent for candidiasis following C. albicans. The opportunistic yeast, $C$. glabrata, is able to cause the critical bloodstream infections in hospitalized patients. Conventional identification methods for yeasts are often time consuming and labor intensive. Therefore, recent studies on sequence-based identification have been conducted. Recently, sequencing the D1/D2 domain of the large subunit ribosomal RNA gene and the internal transcribed spacers (ITS) 1 and ITS2 regions of the ribosomal DNA has proven useful for DNA-based identification of most species of fungi. In the present study, therefore, fungal ITS and D1/D2 domain regions were targeted and analyzed by DNA sequencing for the accurate identification of $C$. glabrata clinical isolates. A total of 102 C. glabrata clinical isolates from various clinical samples including bloodstream, catheterized urine, bile and other body fluids were used in the study. The results of the DNA sequence analysis showed that the mean standard deviation of species identity percent score between ITS and D1/D2 domain regions was $97.8 \% \pm 2.9$ and $99.7 \% \pm 0.46$, respectively. These results revealed that the D1/D2 domain region might be a better target for identifying $C$. glabrata clinical isolates based on DNA sequences than the ITS1 and ITS2 regions. However, in order to evaluate the usefulness of D1/D2 domain region for species identification of all Candida species, other Candida species such as C. albicans, C. tropicalis, C. dubliniensis, and $C$. krusei should be verified in further studies additionally.

Key Words: Candida glabrata, Sequence analysis, D1/D2 domain, Internal transcribed spacers domain, Clinical isolates

Candida species are the most common cause of fungal healthcare-associated infections and, in particular, nosocomial bloodstream infections (BSIs). These organisms are part of the commensal microorganisms in the human body and, rarely cause superficial or systemic fungal infections. Although,
Candida albicans is the most frequently isolated pathogenic yeast in human, the incidence of non-C. albicans infections is also increasing (Katiyar et al., 2016; Amanloo et al., 2018; Kim et al., 2018).

Aside from C. albicans, C. glabrata is presently consi-

Received: October 26, 2018 / Revised: December 7, 2018 / Accepted: December 10, 2018

*Research scientist, ${ }^{* *}$ Graduate student, ${ }^{* * *}$ Professor.

${ }^{\S}$ Equal contributors.

${ }^{\dagger}$ Corresponding author: Sunghyun Kim. Department of Clinical Laboratory Science, College of Health Sciences, Catholic University of Pusan, Busan 46252, Korea.

Tel: +82-51-510-0560, Fax: +82-51-510-0568, e-mail: shkim0423@cup.ac.kr

(C) The Korean Society for Biomedical Laboratory Sciences. All rights reserved.

(c) This is an Open Access article distributed under the terms of the Creative Commons Attribution Non-Commercial License (http://creativecommons.org/licenses/by-nc/3.0/) which permits unrestricted non-commercial use, distribution, and reproduction in any medium, provided the original work is properly cited. 
dered to be the most frequently isolated Candida spp. and constitutes a normal floral yeast in the human gastrointestinal tract, urogenital tract, and oral cavity. C. glabrata causes critical BSIs in hospitalized patients (Byun et al., 2018) and yet, despite its increased incidence, little is known of its molecular structure, epidemiology, and basic biological properties. Its prevalence has increased in the last decade and these species now rank as the second most frequently isolated Candida spp. of all reported candidiasis cases. The increase in the incidence of $C$. glabrata infections is noteworthy because of its decreased susceptibility to fluconazole and the high crude mortality rate associated with BSIs (Andrew et al., 2003).

Traditionally, the identification of Candida spp. has been performed using biochemical analysis, substrate assimilation methods, morphological examinations, or various combinations thereof. To increase ease of identification of Candida spp., commercial tests that use these methods have been created. However, despite the convenience inherent to these methods, the identification of yeasts by conventional applications remains time consuming and labor intensive.

Sequencing the D1/D2 domain of the large subunit RNA gene and the internal transcribed spacer (ITS) 1 and ITS2 regions of the ribosomal DNA (rDNA) has proven useful for the identification of most fungi based on the DNA sequencing. Recent studies have also examined the effectiveness of various molecular identification methods for yeasts using rRNA genes. The ITS1 and ITS2 regions that span the D1/D2 domain have been shown to be the most useful for specieslevel identification of yeasts as a result of variability within these regions. In particular, DNA sequence analysis of these regions has shown great promising in the practice of clinical mycology. The ability to differentiate between clinical yeast isolates obtained from humans has been demonstrated in several large-scale studies following analysis of these regions (Garner et al., 2010).

Therefore, the current study objective was to target and analyze the fungal ITS and D1/D2 domains using DNA sequencing in order to accurately identify $C$. glabrata clinical isolates.

A total of 102 C. glabrata clinical isolates were sourced from the Korean Culture Collection of Medical Fungi (KCMF), Daejeon, the Republic of Korea. Clinical isolates were isolated from various clinical samples, including blood, catheterized urine, bile, and other body fluids (Table 1).

Genomic DNA (gDNA) from $C$. glabrata clinical isolates was extracted using an I-genomic BYF DNA Extraction Mini $\mathrm{Kit}^{\circledR}$ (iNtRON Biotechnology, Seongnam, Republic of Korea) according to the manufacturer's instructions. The concentration and purity of the gDNA was checked by absorbance (Optical density ratio of 260/280) using a NanoDrop ${ }^{\text {TM }} 2,000$ Spectrophotometer $^{\circledR}$ (Thermo Scientific, Waltham, MA, USA) (Da Silva-Rocha et al., 2014). The extracted gDNA was stored at $-20^{\circ} \mathrm{C}$ until use.

The fungal ITS regions, the conserved regions between

Table 1. Sources of Candida glabrata clinical isolates

\begin{tabular}{lc}
\hline \hline \multicolumn{1}{c}{ Clinical specimens } & Number of samples, $\mathrm{n}(\%)$ \\
\hline Peripheral blood & $64(63)$ \\
Catheterized urine & $14(14)$ \\
Others $^{\mathrm{a}}$ & $14(14)$ \\
Bile & $9(9)$ \\
Unknown $^{\mathrm{b}}$ & $1(1)$ \\
\hline Total $^{\mathrm{a}}$ & $102(100)$ \\
\hline
\end{tabular}

${ }^{\mathrm{a}}$ Others: ascitic fluid, joint fluid, pleural fluid, tissue etc.

${ }^{\mathrm{b}}$ No information

Table 2. Oligonucleotide primers for the sequence analysis of the fungal ITS and D1/D2 domain regions

\begin{tabular}{|c|c|c|c|c|c|}
\hline Target regions & Primers & Nucleotide sequences (5' to $3^{\prime}$ ) & $\begin{array}{l}\text { Amplicon size } \\
\text { (bp) }\end{array}$ & $\begin{array}{c}\mathrm{Tm} \\
\left({ }^{\circ} \mathrm{C}\right)\end{array}$ & References \\
\hline \multirow{2}{*}{ ITS } & ITS-F & GTCCTAACAAGGTTAACCTGCGG & \multirow{2}{*}{$970 \sim 980$} & 62.4 & \multirow{2}{*}{$\begin{array}{l}\text { Pryce et al. } \\
\quad(2003)\end{array}$} \\
\hline & ITS-R & TCCTCCGCTTATTGATATGC & & 55.3 & \\
\hline \multirow{2}{*}{ D1/D2 } & NL-F & GCATATCAATAAGCGGAGGAAAAG & \multirow{2}{*}{$600 \sim 650$} & 59.3 & \multirow{2}{*}{$\begin{array}{l}\text { Hesham et al. } \\
\text { (2014) }\end{array}$} \\
\hline & NL-R & GGTCCGTGTTTCAAGACGG & & 58.8 & \\
\hline
\end{tabular}


the $18 \mathrm{~S}$ and $28 \mathrm{~S}$ rRNA, and the D1/D2 domain of the $28 \mathrm{~S}$ rDNA region were amplified and sequenced using each primer pairs (Fig. 1, Table 2). Target amplification was carried out in $20 \mu \mathrm{L}$ of sequenced reaction mixture containing $10 \mu \mathrm{L}$ of Prime TaqPrimix ${ }^{\circledR}$ (GeNet Bio, Daejeon, Republic of Korea), $5 \mu \mathrm{L}$ of distilled ultra-pure water, $1 \mu \mathrm{L}$ of each primer $(10 \mathrm{pmol} / \mu \mathrm{L})$, and $3 \mu \mathrm{L}$ of gDNA template.

The polymerase chain reaction (PCR) protocol comprised initial denaturation at $94^{\circ} \mathrm{C}$ for a minute, 30 cycles of subsequent denaturation at $94^{\circ} \mathrm{C}$ for 30 seconds, annealing at $57^{\circ} \mathrm{C}$ for 30 seconds, and extension at $72^{\circ} \mathrm{C}$ for 45 seconds, followed by final extension at $72^{\circ} \mathrm{C}$ for seven minutes. Two microliters of the PCR products were analyzed by DNA electrophoresis in a $1.5 \%$ agarose gel in tris borate-EDTA (TBE) buffer. Agarose gel electrophoresis of the DNA was conducted using $0.5 \times$ TBE buffer to confirm the presence of the desired product. Thereafter, the amplified product was visualized by staining with SYBR Safe ${ }^{\mathrm{TM}}$ (Invitrogen, Grand Island, NY, USA) under blue-light transillumination. Approximate amplicon sizes were determined using a standard molecular weight marker (100 bp DNA Ladder $^{\circledR}$; iNtRON Biotechnology). The resulting amplicon was purified and

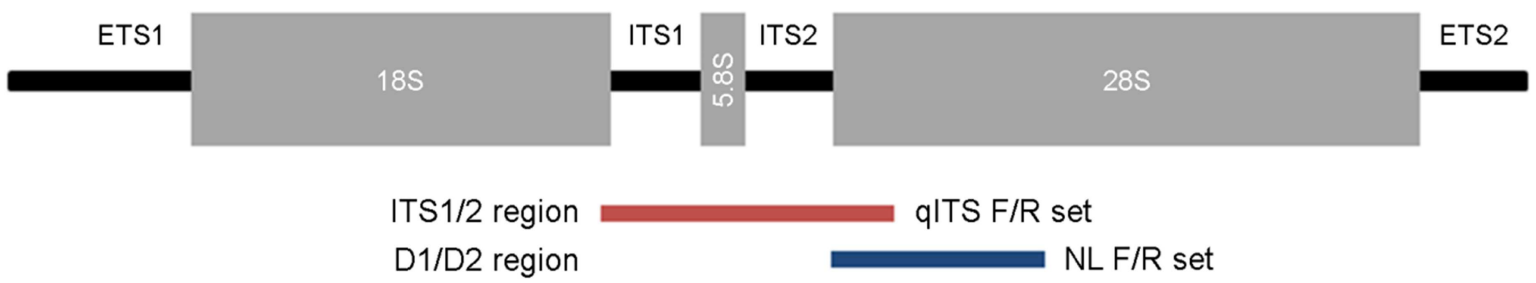

Fig. 1. The target regions of the fungal ITS and D1/D2 domain for the sequence analysis of Candida glabrata clinical isolates.

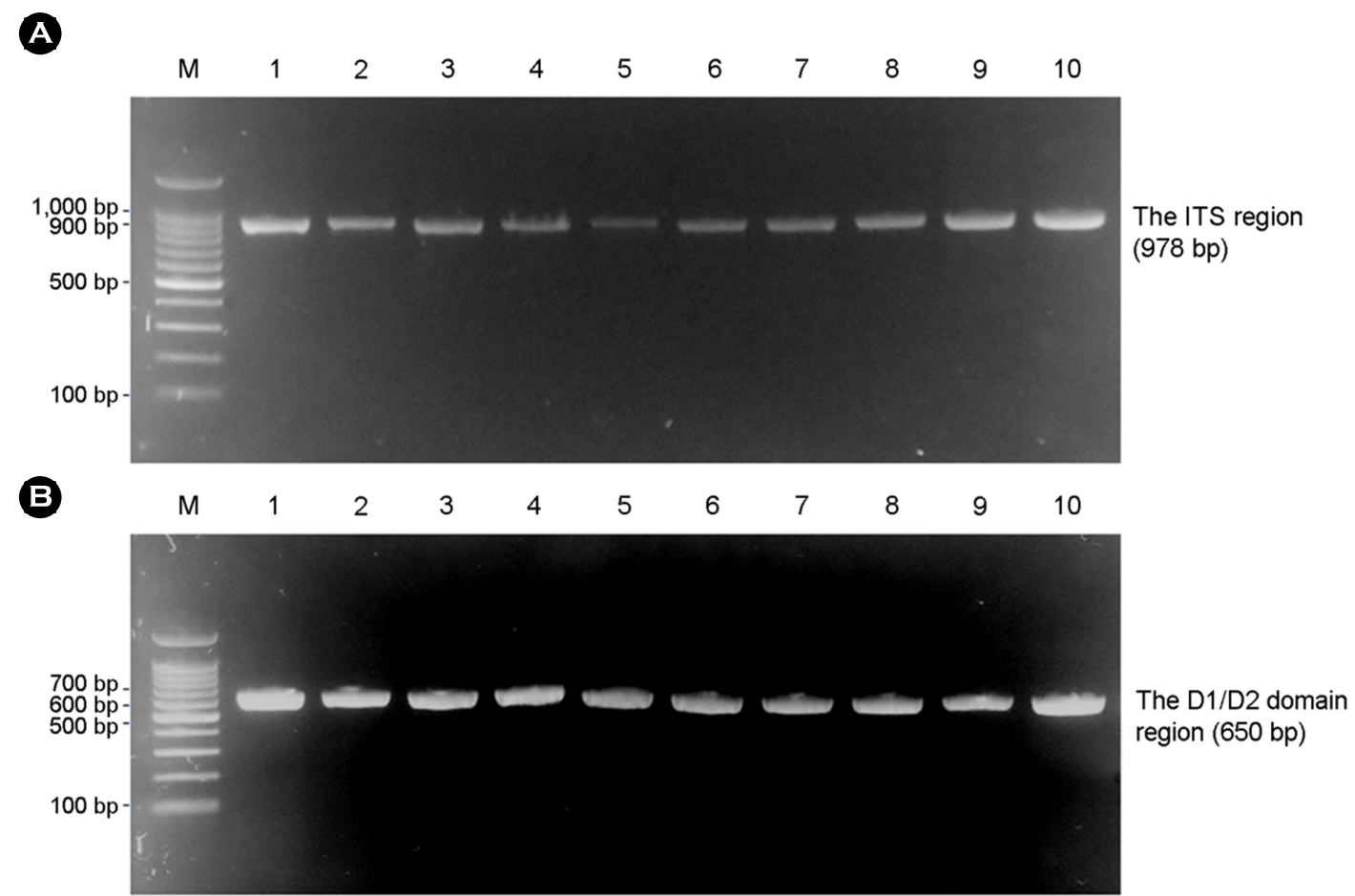

Fig. 2. The results of agarose gel electrophoresis to confirm the target region amplification results before sequence analysis. (A) The amplified fungal ITS domain region analyzed using PCR. M; DNA size marker, lanes 1 10; PCR products (978 bp). (B) The amplified fungal D1/D2 domain region on 28S rDNA analyzed using PCR. M; DNA size marker, lanes 1 10; PCR products (650 bp). 


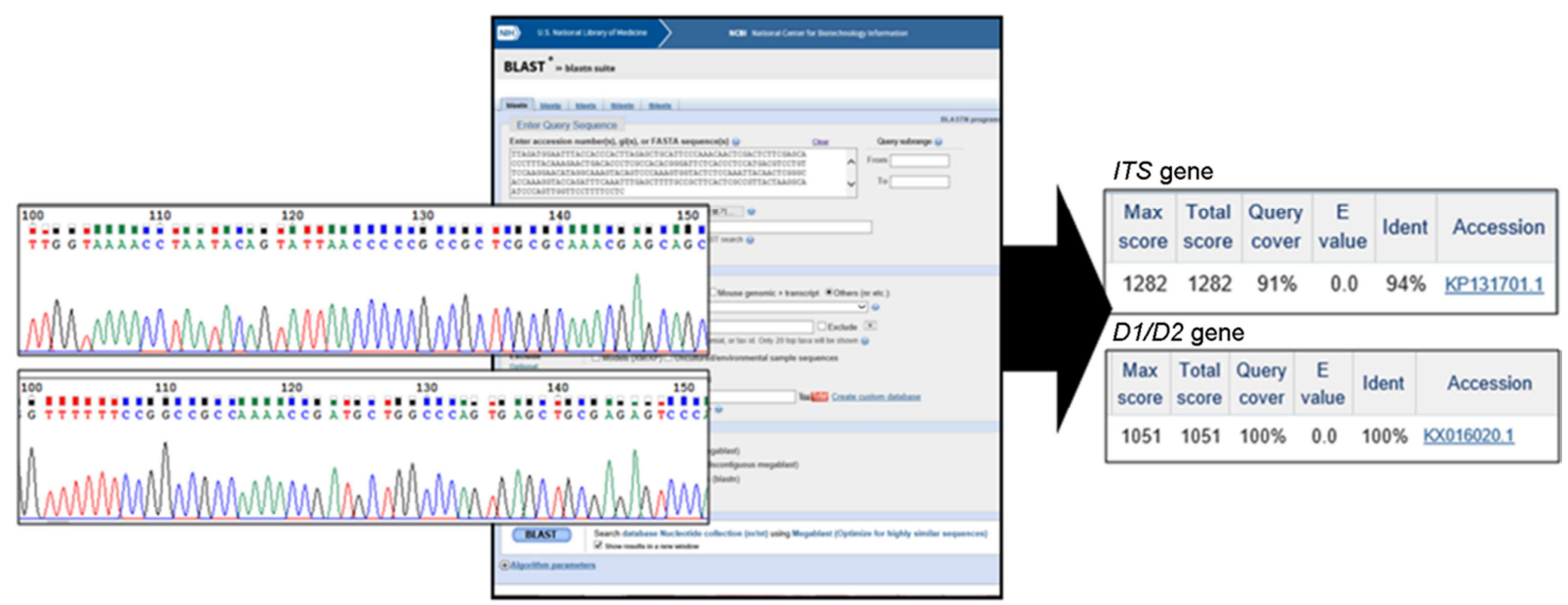

Fig. 3. Results of NCBI Blast analysis with ITS and D1/D2 DNA sequence data. As the result that sequence were aligned with NCBI Blast database, the identity of ITS gene and D1/D2 gene was $94 \%$ and $100 \%$ in the same sample.

sequenced using reverse sequence primer supplied by Macrogen (Daejeon, Republic of Korea). All sequences with low-quality bases in the chromatogram were resequenced to obtain high-quality results. The obtained sequences were aligned with reference sequences in the GenBank database using the Basic Local Alignment Search Tool (BLAST) at the National Center for Biotechnology Information (NCBI) (Fig. 3). The percentage of homology was determined to precisely identify the $C$. glabrata clinical isolates.

The results of PCR and sequencing analysis of the fungal ITS and the D1/D2 domain regions for species identification of Candida spp. were compared. The 1.5\% DNA agarose gel electrophoresis data showed that the sizes of the amplified fungal ITS and D1/D2 domain regions were $978 \mathrm{bp}$ and $650 \mathrm{bp}$, respectively, and that the amplicons had one clear band (Fig. 2). In order to verify the amplified PCR products, they were sequenced and analyzed using the GenBank BLAST. During the comparison, all culture-confirmed clinical isolates used in this study were identified as $C$. glabrata, with high agreement value.

In addition, a comparison was made of the ability of the ITS and D1/D2 domain regions to accurately identify a yeast species using sequence analysis. To this end, both the ITS and the D1/D2 regions of 102 C. glabrata clinical isolates were amplified and sequenced, and the results were analyzed with BLAST. The mean standard deviation (expressed as a
Table 3. Comparison of the accuracy of sequence analysis (BLAST) between in the fungal ITS and D1/D2 domain region for the identification of $C$. glabrata 102 clinical isolates

\begin{tabular}{lcc}
\hline \hline Targeting region & ITS domain & D1/D2 domain \\
\hline $\begin{array}{l}\text { Species identity } \\
\text { percent score }\end{array}$ & $97.8 \% \pm 2.9$ & $99.7 \% \pm 0.46$ \\
$\begin{array}{l}\text { Mean } \pm \mathrm{SD}(\%) \text { for } \\
\text { species }\end{array}$ & & \\
\hline
\end{tabular}

SD: standard deviation

percentage) for the ITS and D1/D2 domain regions for species identification was $97.8 \% \pm 2.9$ and $99.7 \% \pm 0.46$, respectively (Table 3). These results suggest that although the specificity of the results for both regions was similar (over 97\%) and even the amplicon size targeting ITS was much longer than that of D1/D2, the D1/D2 domain region was demonstrated to be a better target for the identification of $C$. glabrata than the ITS region using DNA sequence analysis.

In conclusion, although the D1/D2 domain region was demonstrated to be a better target than the ITS region in identifying C. glabrata clinical isolates, other Candida spp. including C. albicans, C. tropicalis, C. dubliniensis, and C. krusei should also be evaluated in future studies in order to evaluate its usefulness in the identification of all Candida spp. 


\section{ACKNOWLEDGEMENT}

This paper was supported by RESEARCH FUND from Catholic University of Pusan.

\section{CONFLICT OF INTEREST}

No potential conflict of interest relevant to this article was reported.

\section{REFERENCES}

Amanloo S, Shams-Ghahfarokhi M, Ghahri M, Razzaghi-Abyaneh M. Genotyping of Clinical Isolates of Candida glabrata from Iran by Multilocus Sequence Typing and Determination of Population Structure and Drug Resistance Profile. Med Mycol. 2018. 56:207-215.

Byun SA, Won EJ, Kim MN, Lee WG, Lee K, Lee HS, Uh Y, Healey KR, Perlin DS, Choi MJ, Kim SH, Shin JH. Multilocus Sequence Typing (MLST) Genotypes of Candida glabrata Bloodstream Isolatesin Korea: Association with Antifungal Resistance, Mutations in Mismatch Repair Gene (Msh2), and Clinical Outcomes. Front Microbiol. 2018. 9: 1-10.

Da Silva-Rocha WP, Lemos VL, Svidizisnki TI, Milan EP, Chaves

GM. Candida species distribution, genotyping and virulence factors of Candida albicans isolated from the oral cavity of kidney transplant recipients of two geographic regions of Brazil. BMC Oral Health. 2014. 14: 20-28.

Garner CD, Starr JK, McDonough PL, Altier C. Molecular Identifi- cation of Veterinary Yeast Isolates by Use of Sequence-based Analysis of the D1/D2 Region of the Large Ribosomal Subunit. J Clin Microbiol. 2010. 48: 2140-2146.

Hesham AEL, Wambui V, Jo Ho, Maina JM. Phylogenetic Analysis of Isolated Biofuel Yeasts Based on 5.8 S-ITS rDNA and D1/ D2 26S rDNA Sequences. J Genet Engineer Biotech. 2014 12: $37-43$.

Katiyar S, Shiffrin E, Shelton C, Healey K, Vermitsky JP, Edlind T. Evaluation of Polymorphic Locus Sequence Typing for Candida glabrata Epidemiology. J Clin Microbiol. 2016. 54: 1042 -1050 .

Kim HJ, Kim SH, Kim S, Yu YB, Kim YK. Genetic Variations of Candida albicans Isolated from Clinical Specimens Using Multi-locus Sequence Typing Analysis. Korean J Clin Lab Sci. 2018. 50: 331-336.

Pryce TM, Palladino S, Kay ID, Coombs GW. Rapid Identification of Fungi by Sequencing the ITS1 and ITS2 Regions Using an Automated Capillary Electrophoresis System. Med Mycol. 2003. 41: 369-381.

https://doi.org/10.15616/BSL.2018.24.4.430

Cite this article as: Kang MJ, Choi YS, Kim S. A Comparison of the Ability of Fungal Internal Transcribed Spacers and D1/D2 Domain Regions to Accurately Identify Candida glabrata Clinical Isolates Using Sequence Analysis. Biomedical Science Letters. 2018. 24: 430-434. 